\title{
EDUCATING FOR ENGINEERING DESIGN USING DESIGN SCIENCE
}

\author{
W. Ernst Eder \\ Professor (retired), Mechanical Engineering Department \\ Royal Military College of Canada \\ eder-e@rmc.ca \\ Vladimir Hubka \\ c/o Heurista, Postfach 102 \\ $\mathrm{CH}-8028$ Zürich, Switzerland \\ Habib Benabdallah \\ Professor, Mechanical Engineering Department \\ Royal Military College of Canada \\ benabdallah-h@rmc.ca
}

MENDOZA. That is true, sir. A movement which is confined to philosophers and honest men can never exercise any real political influence: there are too few of them. Until a movement shews itself capable of spreading among brigands, it can never hope for a political majority.

George Bernard Shaw, Man and Superman, Act three

\begin{abstract}
Using a description of product development, the general nature of designing for engineering products is discussed. The relationships among theory, method and object are explained. The scope of Design Science is outlined. The needs and methods for designing an engineering system are laid out. Similarly, the needs and methods of education are related to these factors. A brief description of the courses presented at RMC is given to show how this background is used, how students are assessed, and how the courses are evaluated within the given limitations of the college.
\end{abstract}

\section{KEYWORDS}

design theory, design methods, pedagogics and didactics, design engineering

\section{INTRODUCTION}

Designing is usually claimed to be a unifying experience of engineering education. Yet designing is often mis-understood. Most academic staff members have not experienced designing in an industrial environment, and can hardly explain it. There are significant differences in outlook and procedures between science and engineering [1]. Science intends to produce and verify knowledge, independent of its use, engineering has the purpose of creating functioning devices, adding value, even if their way of acting is not fully understood.

Curriculum changes introduced in the 1960's, as a result of the ASEE Grinter Report [2], were in some ways counter-productive. Quoting from Grinter (Appendix): "The Committee considers that scientifically oriented engineering curricula are essential to achieve these ends and recom-mends the following means of implementation." This major report then recommended ten "means of implementation" (something helpful in achie-ving a desired end, Merriam-Webster Dictionary) of which the first three are interesting in the context of this paper:

1) to strengthen the work in basic sciences, including mathematics, physics and chemistry;

2 ) to identify and include six engineering sciences, taught with full use of the basic sciences, as a common core of engineering curricula; and

3 to provide an integrated study of engineering analysis, design, and engineering systems for professional background, planned and carried out to stimulate creative and imaginative thinking, and making full use of the basic and engineering sciences."

The third of these recommendations was expanded to state: "Education directed towards the creative and practical phases of economic design, involving analysis, synthesis, development, and engineering research is the most distinctive feature of engineering curricula. ... Some experience in this 'design' function should be carried in an integrated manner through each semester of the last two years and may be begun earlier if practicable ..."

The Grinter report was written before any serious start had been made on studying procedures, systematic methods and methodologies, modeling tools and theories of designing - a verb describing the necessary and possible activities and processes. Such studies are continuing from about 1955 in Europe. They started at about the same time in the USA, but were neglected between about 1970 and the NSF Initiative [3] in 1985. The implication of the Grinter recommendation is that to stimulate 
creative thinking it would help to study design(s) the word used as a noun describing the resulting hardware (artifacts, products, systems) and working processes (including phenomena and their mathematical models), and only by implication studying the procedures and processes for designing. Newer knowledge about designing has meanwhile been developed. Nevertheless, this part of the recommendations has been sadly neglected - and little attempt has been made to include the more recent systematic-methodical developments.

Meanwhile, computing power has increased dramatically, but we have observed a steady decline in students' understanding and interest in how things work, and in the ability of academic staff to explain contexts and relationships of their own subject to others in the curriculum.

\section{DESIGNING AND PRODUCT DEVELOPMENT}

The current process of 'integrated product development' $[4,5]$ can be divided into operations, which can generally and typically be defined as an iterative and recursive sequencing of:

1) product planning, defining the requirements to be fulfilled by the product, the size ranges to be covered, company conditions, the market and its needs, etc.;

2) designing, establishing in principle and in detail, in advance, what needs to be made or implemented to achieve that product, for all its life phases, sub-divided into:

2a) industrial design, establishing the appropriate appearance, ergonomic properties, and economics, with emphasis on customer appeal;

2b) design engineering, establishing the ways in which the product will function, the components of which it will be made, as well as influencing all other properties of the product;

3) manufacturing a functioning prototype;

4) testing and developing, by adjusting and modifying;

5) correcting the manufacturing documentation;

6) manufacturing planning;

7) test marketing; etc.

Designing is usually treated as 'an art', with little guidance about procedure. This may be applicable to consumer products, which are typically massproduced, and are aimed to please a potential customer by novelty, appearance and other easily assessable factors. Studio techniques, brainstorming, physical modeling and other similar design procedures are usual. Creativity and ideation are paramount, and formal knowledge about design processes is deemed of little use. An appropriate paradigm is that of 'industrial design' and 'integrated product development'. Designing, mainly resulting in artistic renderings of a proposed product, is an important part of product development, and needs little or no (engineering) knowledge from the designer or design team.

Where technical performance matters, the 'art' of engineering is of less use. Creativity and ideation need to be supported by knowledge and methods, and a measure of routine work, which is directed towards achieving an optimal technical system for the intended use. This applies in particular to industrial machinery, whether for manufacturing or for civil engineering construction (etc.), but may also be needed in a durable consumer-product where appearance design is prominent. The machinery must fulfil a (usually well defined and given) purpose, it must function and work effectively, but appearance matters much less. Defining these purposes and functions is usually a task for management and/or a sales department, they determine the product mix offered by an enterprise, and the requirements specification for an individual product (line). Some of these products are designed (as single items, or as small series) for a customer to order, the customer buys a virtual and future product on the reputation of the manufacturing enterprise.

The contrast can best be shown as in table 1 [6].

Design engineering needs to re-interpret the given requirements, (a) so that designers understand the problems, and (b) to incorporate considerations that the requirements specification does not cover. A search for alternative principles of operation and action, modes of construction and manufacture is appropriate, and demands evaluation, analysis and selection. Conventionally, four main phases have been identified:

1) clarifying the problem, transforming a design brief into a preferably comprehensive statement of the requirements;

2) conceptualizing, establishing a promising abstract proposal for solution;

3) embodying, establishing a likely hardware and software system in layout, arrangement, configuration and composition;

4) detailing, establishing the constructional parts to be made to realize the embodiment.

Technical engineering knowledge by the design engineer is an essential component, and designing is usually a separable activity within the product development. Now most machines are hybrids, 


\section{Research Objectives, Design Conditions}

The object to be designed, or the existing (designed) object

Representation and analysis of the object as designed, and its 'captured design intent'

Design process (for the object), methodology, - generating the 'design intent'

Design phenomenology

Responsibilities

Location

\section{Design Engineering}

Technical System; primary: functioning, performing a task

Preparing for manufacture, assembly, distribution, etc., AI, $\mathrm{CAD} / \mathrm{CAM}$

Theories of designing, Design

Science, Formal design

methodologies

Empirical, experimental and implementation studies

Professional, reliability, liability, safety, public, enterprise, stakeholders

Design/Drawing Office

\section{Artistic-Architectural- Industrial Design}

Product; primary: appearance, functionality

Rendering for presentation and display, product range decisions

Intuitive, collaborative, interactive designing

Protocol studies

Enterprise, stakeholders

\section{Table $1 \quad$ Characteristics of Designing}

with electronic control, mechanical, thermodynamic, fluid, chemical (e.g. combustion) and other phenomena interacting.

Iterative working is humanly essential. One reason is the limitation on human short-term memory, to typically $7 \pm 2$ chunks of information $[7,8,9,10]$, which prevents a comprehensive consideration in the mind of any except the simplest problem. The second is that any suggestion or proposal for solving the problem will add to the knowledge and understanding of the problem, and will almost always require a review of any previous results. A forward 'groping' with reflective review characterizes the mode of iterative working. Consequently, each aspiring engineer should acquire a set of competencies as defined in [11]:

- heuristic or practice related competencyability to use experience (precedents [12] and heuristics [13], one's own, and that of others) as guidelines and prescriptions, including knowledge of values (e.g. of technical variables) as initial assumptions;

- branch or subject related competency knowledge of a particular family of technical systems within which designing is expected (which can strictly only be developed once the graduate is employed in designing a particular family of TS), and for this purpose typical examples of families of technical systems should be included in the curriculum (i.e. in addition to conventional and newer machine elements; and the treatment should include not only their engineering sciences, but actual examples of realized systems);

- methods related competency - knowledge of and ability to use specific methods, under controlled conditions of following the methodical instructions (guidelines, prescriptions), and eventually (usually after thoroughly learning the appropriate method) using them intuitively - for diagnostics, analysis, experimentation, information searching, representing (e.g. in sketches and computer models), computer tools and aids, but especially for systematic synthesizing in designing;

- systems related competency - ability to see analytically (reductionistically), and synthetically (holistically) beyond the immediate task, and to take into account the complex situation and its implications, e.g. as in lifecycle engineering, and/or for costs and economics; and

- personal and social competency - including team work, trans-disciplinary cooperation, obtaining and using advice, managing subordinates, social and environmental awareness, micro- and macroeconomic and cultural aspects, etc.

In addition, personal development should take place, and concerns the degree of presence or absence of such factors as confidence, dogmatism and prejudice, impulsiveness, leadership, assertiveness, emotions, autonomy, identity (selfimage), morality, aesthetic sensibility, integrity, purpose, inter-personal relationships, and others. 


\section{THEORY, METHOD, OBJECT}

Methods are generally heuristic [13] prescriptions for action, and help to explore, reformulate, search the solution space, evaluate and choose among the available alternative choices, guide towards a resolution of the problem, etc.

As Klaus [14] formulated in cybernetics (see also [15]), close relationships exist between the subject under consideration (its nature as a product or process), the basic (formalized or informal) theory, and method. The theory should describe and provide a foundation for the behavior of the (natural or artificial, real or process) subject, i.e. it should answer the questions of 'why', 'when', 'where', 'how' - its natural behavior - with adequate and sufficient precision. The theory should also support the utilized methods, i.e. answer the questions of 'how' - procedure, 'to what' - using and/or operating the subject, and for designing the subject. The method should also be sufficiently well adapted to the subject, its 'what' - existence, and 'for what' - anticipated and actual purpose. These three phenomena of theory, method and subject are of equal status to each other. Quoting from Klaus:

'Both method and theory emerge from the phenomenon of the subject.'

If the theory of a subject-region is mature, then the method can be founded in the theory. The theory declares what is in reality the case, the method describes, on the basis of the declared facts, how the scientific and practical activities and behaviors of the humans should take place.

Where no comprehensive theory is available, methods to deal with objects can be proposed, even where the structure of the objects or their behavior is not completely known (this is the cybernetic and newer interpretation).

\section{DESIGN SCIENCE}

Design Science [16], a scientific formulation (theory) of the knowledge about designing and the objects to be designed, is built on the system view of cybernetics and uses a series of terms and statements in the same or similar sense: system, structure, function, strategy, tactics (see [17]).

The structure of a system determines its capability to function (and/or its way of functioning, its mode of action) and its behavior. The desired function (or behavior) does not uniquely determine the structure capable of realizing this function, it can usually be realized by several considerably different structures. Designing, a synthesizing relationship, consists in essence of trying to fulfill the desired function and behavior by proposing (and analyzing) suitable structures.

Design Science [16] is augmented by some more detailed and concrete theories concerning the technical system [18] (as the object to be designed), and the design process. The theories are summarized and illustrated by many models (mainly graphical representations), and these are the basis for (or are directly used as) methods that can be adapted and applied for designing. A somewhat more practice-oriented treatment of the combined problem range was published [19], and supported by case examples of conceptualizing [20]. Problems of education for designing and creativity, especially the necessary pedagogics and didactics (theory and method of education), have also been investigated $[21,22]$.

\section{APPLICATION TO DESIGNING}

The methods of engineering include not only the analysis to investigate and predict the object's (i.e. the product's) behavior, but also (more important for this paper) the methods of designing, which include both pragmatic methods, and methods based on (or improved using) Design Science [16]. Nevertheless, no method can be applied unless it has been modified and adapted to the problem and the situation in which the problem is to be solved.

Design engineering involves some flair, ability, intuition, creativity [22], spontaneity, etc. (and consequently some mystery), but also judgment, reflection [23,24], conjecture and case-based reasoning, feel, and experience of designers (some of these may even be computer-assisted). It is necessarily heuristic [13], iterative, recursive, opportunistic, flexible, and idiosyncratic. Teamwork among designers and other participants plays a large role in the design process. All these are essential to designing, but as individual statements none of them captures the essence of designing, they are necessary, but not sufficient conditions. They seem to indicate that designing is purely a very personal and human matter. But design engineering concerns an activity performed within an organization and under specific circumstances, and about an object - a product, a technical system. Some coherent and comprehensive systematic-methodical procedures are available from and within Design Science [16], and are useful, if applied appropriately and flexibly. Other attempts to provide methods exist, they prescribe parts of the process (e.g. 'industry best practice' methods), usually without a theory of either the design process or the object being 
designed. Yet only a planned and conscious (but iterative and recursive) designing procedure can ensure that an optimal solution of the presented problem can be approached in an effective process. The transformation process as defined in Design Science [16] can be used as a basis for designing, to define a comprehensive design methodology:

a) When a designer has understood the transformation system and process (black box, a subject and its theory), figure 1 , he/she can apply the appropriate method. This consists of a chain of (intermediate) goals for which means of solving should be found, where each means is a goal for the next step:

- determine the essential tasks of the transformation process,

- choose a favorable technology,

- establish all necessary output effects of the operators (input effects to the operands needed for transforming them),

- and distribute these optimally among the humans and the technical system in the existing situation, i.e. establish the technical process.

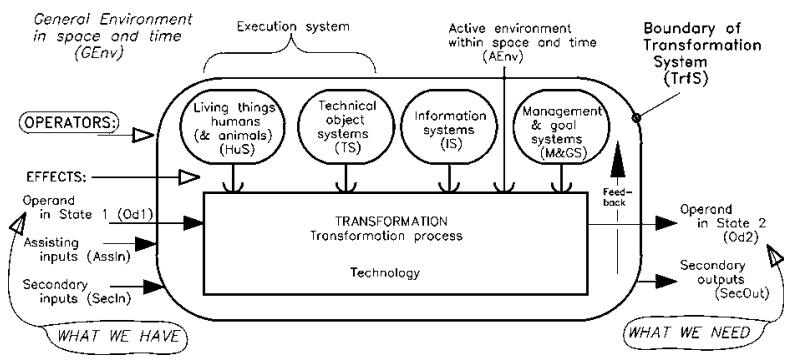

Figure 1 General Model of a Transformation

This method is preferably used in clarification of the design task (see above) although it belongs into the solution process (conceptualizing phases). If an opportunistic and intuitive step is taken outside this procedure, at least a check should be made to ensure that the results do not violate the procedural considerations and outcomes.

b) The origination and life of the technical system (its life cycle) can be represented by a sequence of models of the transformation system, see figure 2. The areas of Design for $X-D f X$ [25] present the search field for properties of the technical system to be designed, see figure 3 , which is also the basis for writing a design specification, as output from clarification of the design task.

c) Conceptualizing, embodying, and detailing, establishing the internal properties (figure 3), can be helped by the theoretical models of technical systems, see figure 4 . From the method described in a) above, another goals-means chain can be traversed:

- the needed (internal and trans-boundary) functions of the system can be established, the function structure;

- organs capable of fulfilling the functions can be delineated (e.g. by a morphological matrix) and combined to establish an organ structure - the goal of conceptualizing;

- preliminary layouts can be explored, part of establishing the constructional structure;

- dimensional layouts generated; this is the goal of embodying;

- details established, finally establishing the constructional structure;

- parts lists generated; etc.

At each step in the chain, several alternative solution proposals can be found, and the most appropriate selected for further processing.

In all these processes of designing, the information can be processed in verbal, graphical (informal sketching, formal drawing, computer-aided modeling), and/or symbolic media form. Coordinated use of these three media is preferred. Any formulation of an intermediate goal should continually be reviewed, and if needed revised, to make the statement less ambiguous and the solution process easier. The design brief and the design specification should also be periodically reviewed, to check that the intermediate proposals and final selected solution conform to the set problem which itself may need to be reviewed. The process of designing involves application of a repeated cycle of problem-solving steps to achieve progress in transforming the input into the output.

It should now be obvious that systematic methods present no restrictions on creativity, intuition, opportunism, reflection, incubation, decisionmaking, teamwork, etc. The myth that system and method destroys creativity can be laid to rest.

\section{APPLICATION TO EDUCATION}

Courses in engineering are now mostly taught in isolation, as analytical, mathematics-based scientific disciplines. Yet the search for alternative solution principles involves searching among all the sciences, and using experience from existing machinery. A better arrangement of engineering knowledge for designing would be to collect the different principles and phenomena that can deliver a desired output effect - the scientific disciplines are not suitable for a search for alternatives [26].

Humanities are 'tacked on' to the engineering 


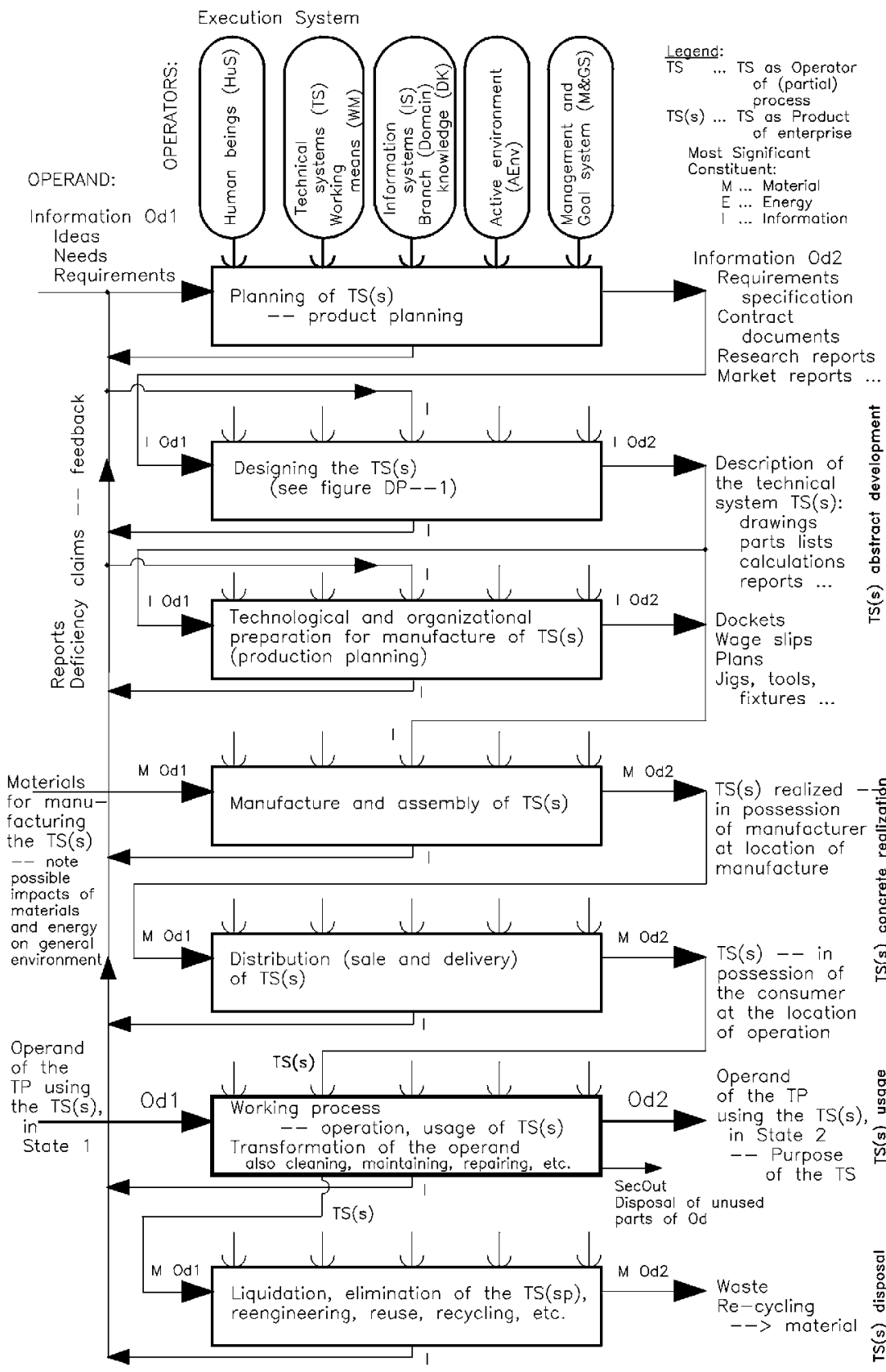

are more closely allied to research than to designing. Unification in this way is almost impossible to achieve. It would remain for inexperienced students to recognize the connections for themselves $-\mathrm{a}$ difficult task in itself, especially whilst trying to learn the subject matter.

Many different factors are involved in education, including the students, teachers and support staff, teaching and learning equipment, information about teaching/learning (pedagogy and didactics), information (knowledge, abilities, skills and attitudes to be modified by teaching), educational management, and the edu-cational environment. Again, there should be a coordinated system of (education) theory, method (of education) and subject (education) -- applicable for each of the factors involved in education.

In our efforts to teach (and the students' efforts to learn) design engineering, we must present a coherent, comprehensive theory of $\frac{n}{n}$ designing, in sufficient depth to explain the methods we recommend during designing. Our recommenda-tion is to use Design

Science [16] as the theoretical basis. We must also provide practical worked examples (e.g. [20]), preferably of conceptualizing and of re-designing. Projects of progressively increasing difficulty and complexity, preferably performed throughout the years of कo engineering education, and under guidance, will then create the experience of using these methods. The theory, methods, examples and practice should be introduced in suitable stages. A useful guideline, attributed to Confucius, says:

Tell me and I will forget

Show me and I will remember

Involve me and I will understand

Take one step back and I will act.

The first two of this set of items are often used to advocate that only project-based education leads to learning. The last of these items is usually omitted - and, according to the same logic, would lead to rejection of project-based learning. These four statements are mutually supporting, synergistic and
A 'capstone design' course often claims to unify the curriculum by a project, again with little guidance about procedures. Many of these projects 


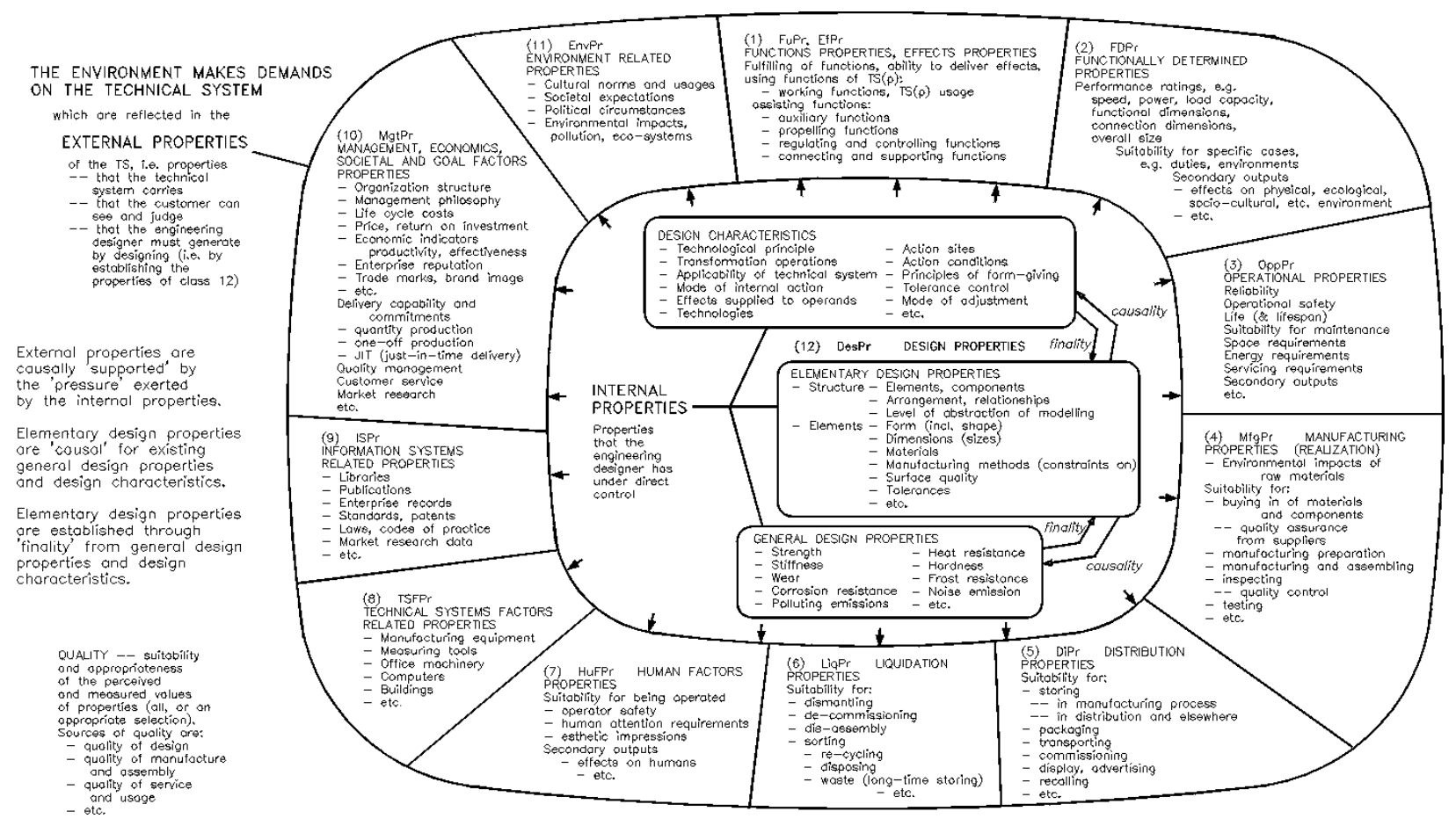

Figure 3 Classes of Properties of Technical Systems and their Relationships

additive. Inducing learning requires a combination of explanation (telling), demonstration (showing), coaching (involving), and release from supervision (stepping back):

Do all four and I will become competent.

The goals for teaching should be elaborated in reasonable detail to guide this design engineering teaching. This comprehensive consideration of design process, product, theory, method and the human should take place during the whole of engineering education, throughout the (2, 3 or 4$)$ years of the course, not just in specific design courses, especially not just in capstone courses.

Students must be encouraged and induced to use the recommended methods as fully as possible. Students should not be allowed to use the methods rigidly - to hide behind the procedures without actually producing useful results. They should be encouraged (and shown how) to redefine, clarify, reformulate, combine or divide, and manipulate their structures (e.g. transformation operations, system-internal functions, layout features, parts features, etc.) for their problem, especially if they find difficulty in using them for solving the problem.

If students do not meet these systematic methods during their education, they are unlikely to encounter them in their future practice, and will likely be resistant to using them. It takes a generation or more for infiltration to take effect, maybe 30 years.

\section{COURSE CONDUCT AT RMC}

The structure of undergraduate teaching at the Royal Military College of Canada (RMC) is that students only specialize in engineering in their third (Junior) and fourth (Senior) years. The third-year course (MEE/GMF 303) is compul-sory for mechanical engineering students (about 30 anglophones and 10 francophones), the fourth-year course (MEE 403 - unilingual) is an elective.

Our goal is to induce the students in each course (working in small groups of 2 to 4) to follow the systematic design method step by step, bringing each step as far as possible towards completion. At the same time, we advise them about the relationships of each step to the presented theory. Iteration and recursion are encouraged where needed. We also discuss the possible advantages and disadvantages of their procedures, and of their formulations (graphical, symbolic and verbal) for the intermediate solutions that they produce towards solving the problem. Mini-projects are taken from defining the problem in the form of a design specification, step by step into a sketch layout, and if possible into a dimensional layout. Further processing into detail drawings would take up too much time, with too 


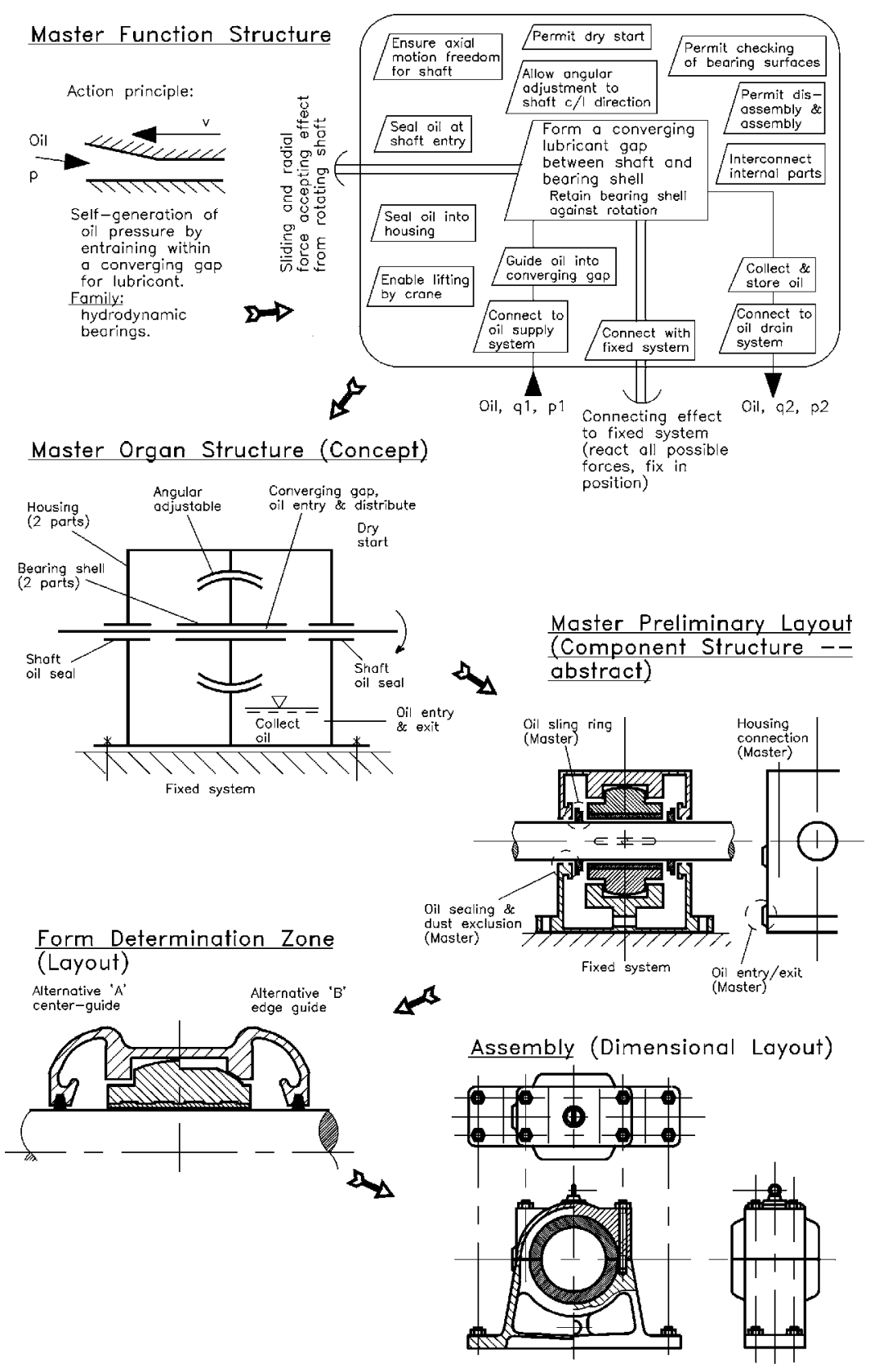

The other periods in each course are used for hands-on activities. In the third-year course, the activities consist of two re-designing mini-projects, a paper project, and a design-build-test project, usually of a balsa-wood structure or device, students working in groups of about three. In addition, a three hours final examination is used, consisting of two parts, a re-design problem, and essay-style questions about the lectures.

In the fourth-year course, the two mini-projects are novel products to be designed, using the full sequence of steps outlined above, up to a reasonable preliminary layout, in sketch form. Both mini-projects are used to assess student learning, together with a final examination similar to the one for the third-year course.

Again due to the circumstances at $\mathrm{RMC}$, evaluation of this course sequence is difficult. The francophone section runs parallel with the anglophone section, instructed by different instructors. According to our regulations, examinations are common between the sections. Student evaluations of these courses are generally positive, with compliments usually coming from those cadets who have had practical experience outside the academic world.

Feedback from colleagues about effects on other courses (mainly immediately after 1992) were positive: students worked more

Figure 4 Models of Technical Systems: Example Journal Bearing

little learning (at the third- and fourth-year levels) for the graduates' anticipated practice.

Four periods per week are allotted during one term (of 14 weeks) to each design course. In each of the two design courses, we usually spend one or two periods per week lecturing, using pre-printed handout material. The subject matter covers aspects of design theory, and some topics related to manufacturing, management, standards, 'best practice' methods, ergonomics, economics, tolerancing, etc. effectively on their capstone projects, and use some of the models, methods and terminologies. Similar feedback also comes from students.

\section{CLOSURE}

For industrial design it may be sufficient to teach by projects and studio work alone, but inclusion of the Design Science basics and methods would be a useful addition. We claim that teaching for design engineering should include an adequate treatment of theory and of methods, and of demonstrations by examples, based on Design Science. A studio experience may be a useful 
addition. Only in this way will the full benefit of these methods enter industry, and the effects can only be expected after a sufficiently long time. Unfortunately, Design Science and its methods still only exist among the "philosophers and honest men', we continually hope for interest from some 'brigands'.

\section{REFERENCES}

[1] Eder, W.E., "Engineering Design - Art, Science and Relationships", Design Studies Vol. 16, No. 1, January 1995, p. 117--127

[2] - ASEE, Report on Evaluation of Engineering Education (L.E. Grinter, chairman), Jnl. Engng. Educ., Sept 1955, p. 25-60

[3] - NSF, National Science Foundation : Program Announcement "Design Theory and Methodology", Nr. OMB 3145-0058 12/31/85

[4] Andreasen M M and Hein L Integrated Product Development IFS Publ London and Springer-Verlag Berlin/Heidelberg (1987)

[5] Ehrlenspiel K Integrierte Produktentwicklung (Integrated Product Development) Carl Hanser Verlag Munich (1995)

[6] Eder, W.E. (2004) "Integration of Theories to Assist Practice", in Proc. IDMME 2004, $5^{\text {th }}$ International Conference on Integrated Design and Manufacturing in Mechanical Engineering, University of Bath, UK, on CDROM

[7] Miller G A 'The Magical Number Seven, plus or minus two: Some Limits on our Capacity for Processing Information' Psychological Review Vol 63 (1956) pp 81 - 97

[8] Miller G A 'Information and Memory' Scientific American Vol 195 (1956) pp 42 - 46

[9] Miller G A 'Human Memory and the Storage of Information' IRE Trans. on Information Theory Vol IT-2 No 3 (1956) pp 128 - 137

[10] Miller G A 'Assessment of Psychotechnology' American Psychologist Vol 25 No 11 (1970) pp $911-1001$

[11] Pahl, G. (scientific director), 'Ergebnisse der Diskussion' (Results of the Discussions), in G. Pahl (ed), Psychologische und pädagogische Fragen beim methodischen Konstruieren Ladenburger Diskurs (Psychological and Paedagogic Questions of Methodical Designing), p. 1--37, Köln: Verlag TÜV Rheinland (1994)

[12] Booker, P.J., 'Principles and Precedents in Engineering Design', London: Inst. of Engineering Designers (1962)

[13] Koen B V Discussion of the Method Oxford University Press, New York (2003)

[14] Klaus G Kybernetik in philosophischer Sicht (Cybernetics in Philosophical View) 4th ed Dietz Verlag, Berlin (1965)

[15] Ashby W R An Introduction to Cybernetics Methuen Univ. Paperbacks, London (1968)

[16] Hubka, V., \& Eder, W.E. (1996) Design Science: Introduction to the Needs, Scope and Organization of Engineering Design Knowledge, London: Springer-Verlag
http://deed.ryerson.ca/DesignScience/

[17] Klaus G Wörterbuch der Kybernetik (Dictionary of Cybernetics) Fischer, Frankfurt (1969)

[19] Hubka V and Eder W E Theory of Technical Systems Springer-Verlag, Berlin and New York (1988)

[19] Hubka V and Eder W E Engineering Design Heurista, Zürich (1992)

[20] Hubka V, Andreasen M M and Eder W E Practical Studies in Systematic Design Butterworths, London (1988)

[21] Eder, W.E., Hubka, V., Melezinek, A. \& Hosnedl, S. (1992) WDK 21 - ED Engineering Design Education - Ausbildung der Konstrukteure - Reading (Zürich: Heurista)

[22] Eder, W.E. (editor) (1996) WDK 24 -- EDC -Engineering Design and Creativity -Proceedings of the Workshop EDC, held at Pilsen, Czech Republic, November 1995, Zürich: Heurista

[23] Schön, D.A. (1983) The Reflective Practitioner: How Professionals Think in Action, Basic Books, New York

[24] Schön, D.A. (1987) Educating the Reflective Practitioner: Towards a New Design for Teaching and Learning in the Professions, San Francisco: Jossey-Bass

[25] Hosnedl S, Borusikova I and Wilhelm W "TQM Methods from the Point of View of Design Science", in WDK 25 -- Proceedings of the International Conference on Engineering Design, ICED 97 Tampere Tampere University of Technology, Tampere, Finland (1997)

[26] Eder, W.E., "Engineering Design - Mediating a Transition from Science to Engineering", in Proc 1996 Canadian Conference on Engineering Education, Kingston, $\mathrm{ON}$ : Queen's University, 1996, p. 253-258 